\title{
Patellar sleeve avulsion fracture in a patient with Sinding-Larsen-Johansson syndrome: a case report
}

\author{
Andrés Schmidt-Hebbel ${ }^{1}$, Felipe Eggers ${ }^{2 *}$, Vincent Schütte ${ }^{3}$, Andrea Achtnich ${ }^{2}$ and Andreas B. Imhoff ${ }^{2}$
}

\begin{abstract}
Background: Patellar sleeve avulsion (PSA) fractures are rare injuries that occur in in skeletally immature patients. Initial diagnosis is key to a successful outcome, as these injuries are easily overlooked on plain radiographs with poor results well documented from delayed management. High index of suspicion from the mechanism of injury, thorough clinical examination and Magnetic Resonance Imaging (MRI) help to avoid misdiagnosis.

Case presentation: The case of a 12-year-old male athlete with an acute PSA after a conservative treatment of a $S L J$ syndrome is described. The patient was referred to our clinic due to severe pain and loss of function after performing a high jump. Plain radiographs (X-ray) and MRI confirmed an inferior pole PSA which was fixed with double trans osseous ultra-high strength tapes. At the 3-month follow- up visit the patient was able to ambulate brace free. At 2-years follow up the patient was able to play soccer and ice hockey. To our knowledge, there are no case reports of inferior pole PSA with prior SLJ syndrome described in literature.

Conclusions: Early clinical suspicion and distinguishing this PSA from other enchondral ossification disorders around the knee is critical to avoid misdiagnosis. Whether SLJ syndrome increases the risk of sustaining a PSA is still not clear. Trans osseous fixation with suture tapes leads to good functional results in a young athlete with inferior pole PSA.
\end{abstract}

Keywords: Sleeve fracture, Patellar avulsion, Sinding-Larson-Johansson, Fiber tape, Surgical technique

\section{Introduction}

Patellar sleeve avulsions (PSA) are rare injuries that occur in children and adolescents, and represent less than $1 \%$ of all pediatric fractures $[1,2]$. Most reported cases of PSA involve the inferior patellar pole, but less frequent bilateral and superior pole fractures have also been reported [3, 4]. The peak incidence of sleeve fractures in children is 12.7 years, with a range of 8 to 16 years [5-7]. At this age the patella is more hypermobile, and the relatively high cartilage-bone ratio at the transformation zone

\footnotetext{
* Correspondence: pipe.eggers@gmail.com

${ }^{2}$ Technical University of Munich. Klinikum rechts der Isar, Abt. f. Sportorthopädie- Ismaninger Str. 22, 81675 Munich, Germany

Full list of author information is available at the end of the article
}

makes it more vulnerable to acute and chronic eccentric loads and shear forces. The main mechanism of injury in PSA is indirect, acute forceful muscle contraction of the quadriceps muscle typically seen during jumping activities $[8,9]$.

In the literature, there is a limited data regarding treatment options and outcome for PSA. The main goal is to achieve a functional extensor mechanism, which can be accomplished through conservative treatment in the cases of non-displaced avulsion. Displaced PSA treated non operatively may lead to complications like patella alta, anterior knee pain or loss of quadriceps function, and therefore it is important to be aware of this rare injury. Subtle bony avulsions on plain radiographs might be easily

(c) The Author(s). 2020 Open Access This article is licensed under a Creative Commons Attribution 4.0 International License, which permits use, sharing, adaptation, distribution and reproduction in any medium or format, as long as you give appropriate credit to the original author(s) and the source, provide a link to the Creative Commons licence, and indicate if changes were made. The images or other third party material in this article are included in the article's Creative Commons licence, unless indicated otherwise in a credit line to the material. If material is not included in the article's Creative Commons licence and your intended use is not permitted by statutory regulation or exceeds the permitted use, you will need to obtain permission directly from the copyright holder. To view a copy of this licence, visit http://creativecommons.org/licenses/by/4.0/ The Creative Commons Public Domain Dedication waiver (http://creativecommons.org/publicdomain/zero/1.0/) applies to the data made available in this article, unless otherwise stated in a credit line to the data. 


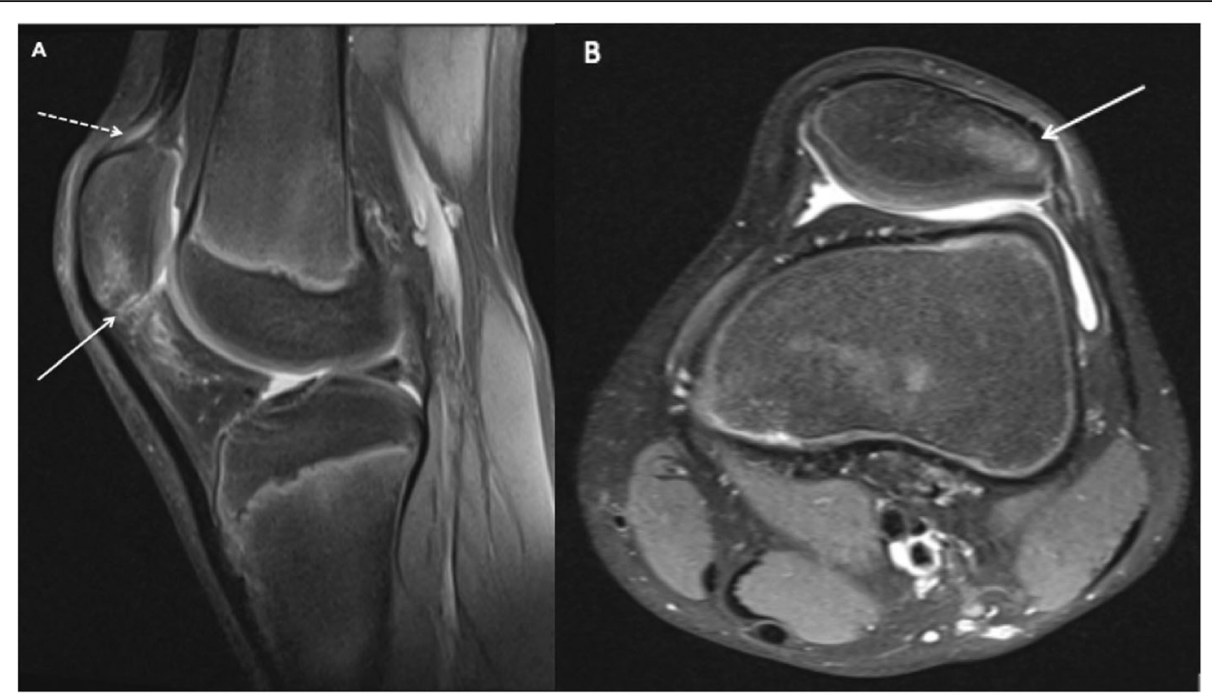

Fig. 1 T2-weighted MRI 4 months prior to acute injury. a: Increased bone signal of inferior patellar pole (straight white line) and quadriceps tendinosis (dotted white line). b: Increased bone signal in lateral patellar facet compatible with bone edema (straight white line)

overlooked. A high index of suspicion from the mechanism of injury, thorough clinical examination and Magnetic Resonance Imaging (MRI) help to avoid misdiagnosis [2].

The present case report describes relevant clinical details, imaging and the surgical treatment of an inferior pole PSA fracture in a 12-year-old athlete with previous Sinding-Larsen-Johansson (SLJ) syndrome. To our knowledge, there are no case reports of inferior pole PSA with prior SLJ syndrome published in literature. The patient and his family were informed that data concerning the case would be submitted for publication, and our institutional review board approved the study.

\section{Case presentation}

We describe the case of a healthy 12-year-old male athlete with SLJ syndrome and acute PSA. The patient reported chronic anterior knee pain 4 months before related to repetitive high jumping activity. Clinical findings and MRI were compatible with SLJ syndrome (Fig. 1). The patient's activity level was reduced to a minimum, and after 3 months of conservative treatment he initiated high jumping activity.

Four months following the first symptoms of SLJ syndrome, the patient reported severe knee pain and loss of function after performing a high jump. He was referred to our outpatient clinic with a swollen,

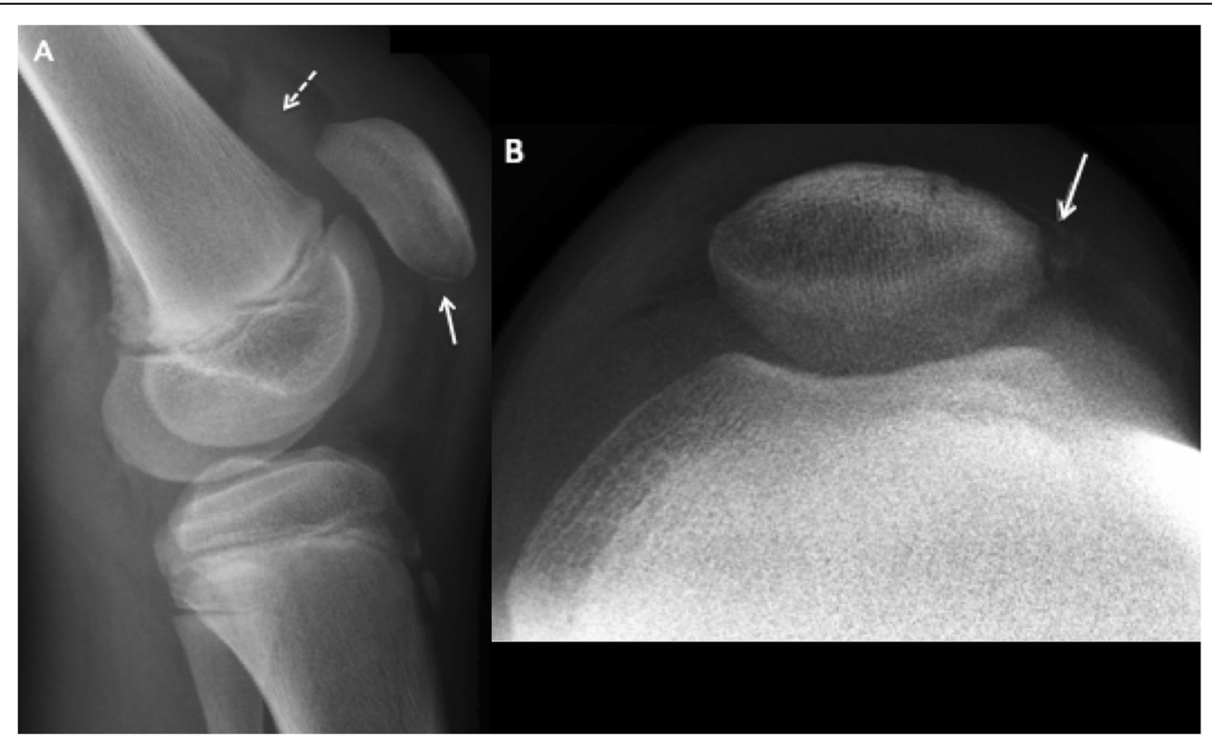

Fig. 2 a: Minimal avulsion fracture of inferior patellar pole (straight white line) and large intra-articular effusion (dotted white line) on lateral X-ray. b: Sunrise view demonstrating lateral retinacular avulsion (straight white line) 


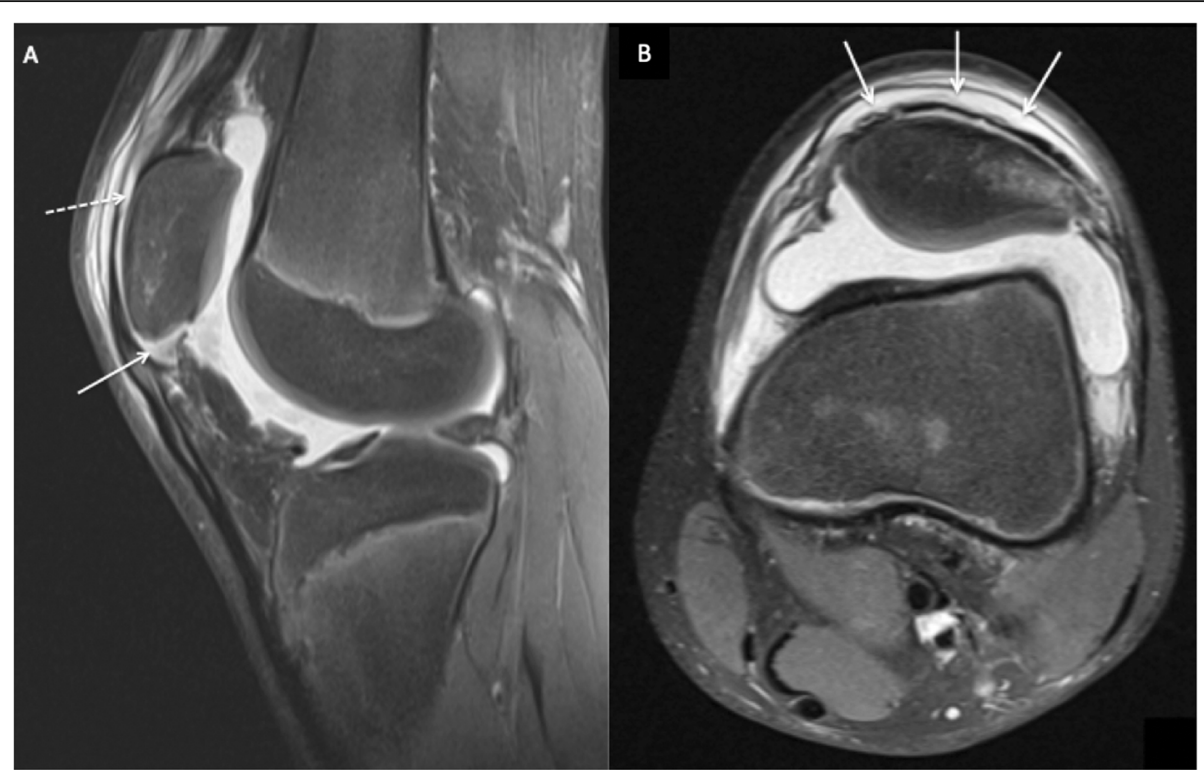

Fig. 3 a: Sagittal T2-weighted MRI after acute injury showing patellar tendon sleeve avulsion (straight white line) with sub periosteal-fluid surrounding the patella (dotted white line). b: Axial T2- weighted MRI demonstrating sub-periosteal fluid (straight white line) communicating with the intraarticular effusion

painful left knee and difficulty with weight bearing. Examination revealed haemarthrosis with tenderness over the patella, limited range of motion and a palpable defect of the patellar tendon. The patient was unable to perform a straight-leg raise. Plain radiographs (X-ray) and MRI confirmed an inferior pole PSA (Figs. 2 and 3), and surgery was indicated.

Under general anesthesia, the PSA was fixed with double trans osseous ultra-high strength tapes. A midline skin incision was used. The subcutaneous layer and the bursa were incised sharply showing a bloodinfiltrated periosteum, which was incised longitudinally. Careful surgical exposure is mandatory to avoid transient ischaemic changes or an avascular necrosis of the proximal pole, because the blood supply of the immature patella originates predominantly from the anterior surface of the distal pole [8]. The entire periosteum was torn from inferior patella pole and peeled off the

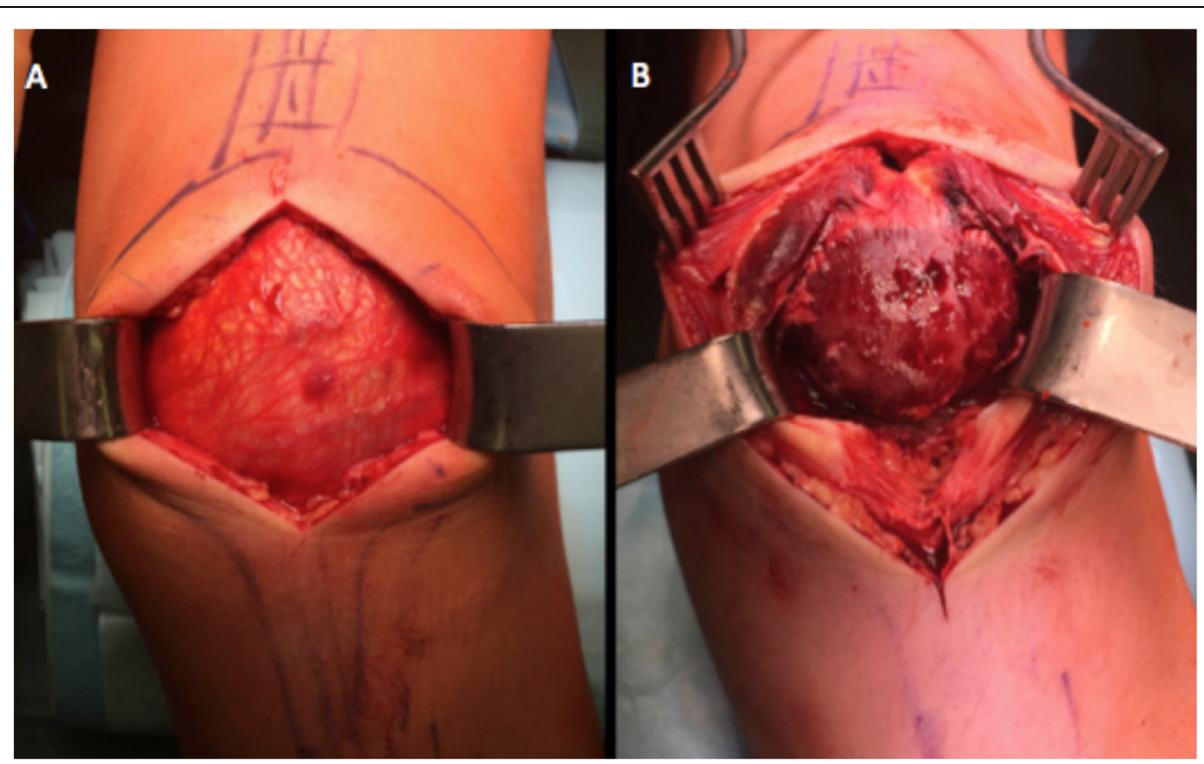

Fig. 4 Intraoperative pictures a: Intact prepatellar bursa. b: Prepatellar bursa and periosteum sharply dissected. The patellar tendon was avulsed off the distal pole and anterior aspect of blood infiltrated patella, with an intact proximal patellar pole and quadriceps tendon 


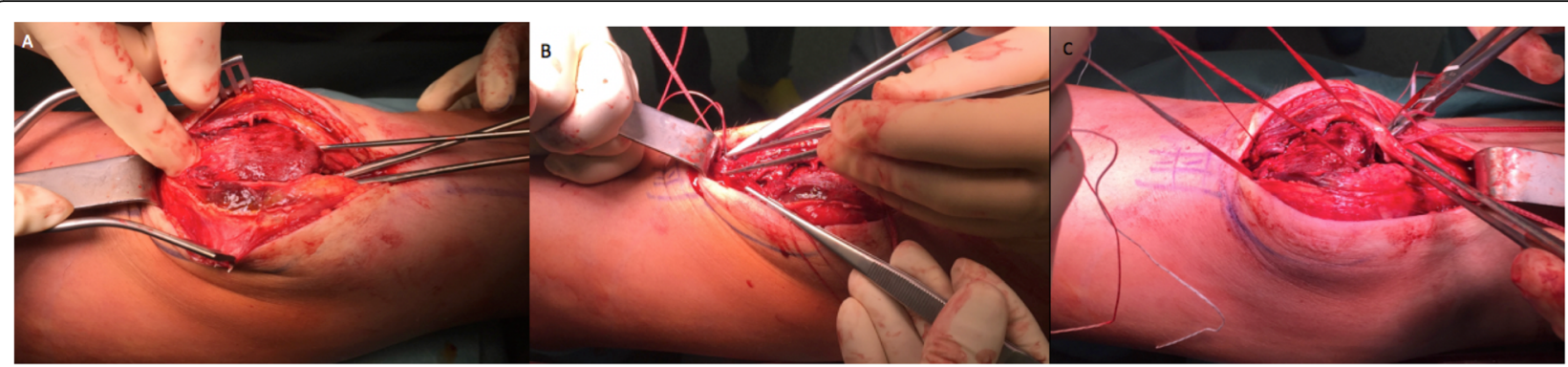

Fig. 5 a: Two vertical patella bone tunnels were drilled from distal to proximal. b: One end of a FiberTape ${ }^{\circledast}$ was passed through the lateral tunnel from distal to proximal and whipstitched the distal quadriceps tendon. c: A TigerTape ${ }^{\mathrm{TM}}$ suture (Arthrex, Naples, Florida) was passed from distal to proximal, one end in each tunnel, and both ends were held over the proximal pole. The FiberTape ${ }^{\varpi}$ was shuttled down the medial patellar bone tunnel and whipstitched the proximal patellar tendon where it was tied down in $90^{\circ}$ of flexion

anterior patellar surface. The superior patellar pole and quadriceps tendon insertion were intact (Figs. 4a and b). Two vertical bone tunnels were drilled in the patella (Fig. 5a). A FiberTape ${ }^{\oplus}$ was first used, with one end passed through the lateral tunnel from distal to proximal and whipstitched the distal quadriceps tendon (Fig. 5b). A TigerTape ${ }^{\mathrm{TM}}$ suture (Arthrex, Naples, Florida) was then passed from distal to proximal, one end in each tunnel (Fig. 5c). The FiberTape ${ }^{\oplus}$ was shuttled back down the medial patellar tunnel and whipstitched the proximal patellar tendon where it was tied down in $90^{\circ}$ of flexion (Fig. 5c). Both ends of the TigerTape ${ }^{\mathrm{Tm}}$ were used to close the periosteum from proximal to distal over the anterior patellar surface in a shoestring suture technique and tied down over the proximal patellar tendon (Fig. 6a and b).

Postoperatively, the knee was immobilized with a locked knee brace (M.4 X-lock ${ }^{\ominus}$, MEDI) in full extension and weight bearing was restricted for 6 weeks. The postoperatively X-ray showed a correct patellar height (Fig. 7). Physical therapy was started immediately with full passive range of motion. At seven weeks postoperatively, the patient began active range of movement and partial weight bearing with $20 \mathrm{~kg}$ increments per week. At the 3-month follow- up visit the patient was able to ambulate brace free. Control MRI shows a healed periosteum and patellar tendon (Fig. 8). At 2-years follow up the patient described to be able to play soccer 3 times a week in the soccer club without pain. Ice hockey was also played without problems. Only slight pain by prolonged sitting and slight atrophy was described. The Kujala score at 2-years follow up was 96, Lysholm score 100, Tegner score 9, and VAS score 0.

\section{Discussion}

The most important finding of the present case report is the occurrence of a PSA from the distal pole

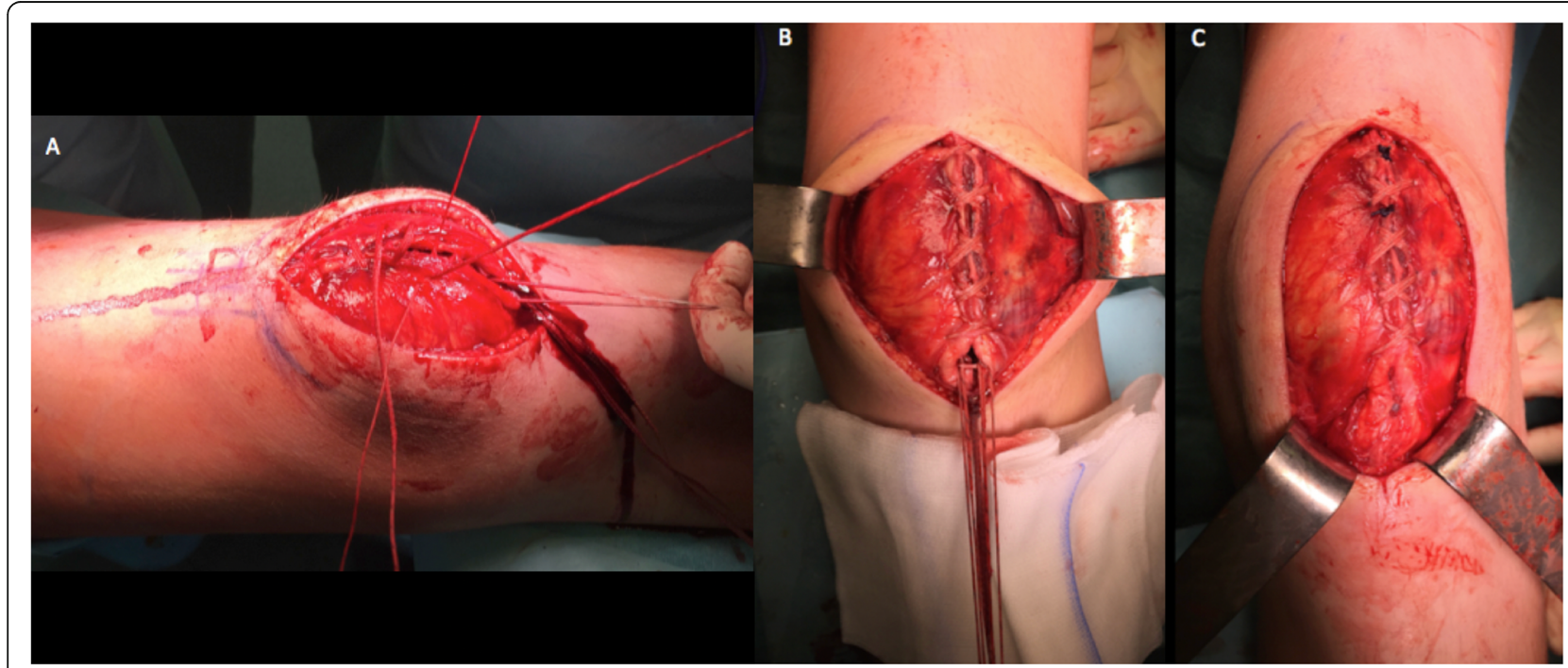

Fig. $\mathbf{6}$ a and $\mathbf{b}$ : Shoelace suture of both ends of TigerTape ${ }^{\mathrm{TM}}$ closing the distal quadriceps tendon and periosteum over the patella. c: Final aspect of left knee after the TigerTape ${ }^{\mathrm{TM}}$ was tied onto the proximal patellar tendon and hidden beneath the periosteum 


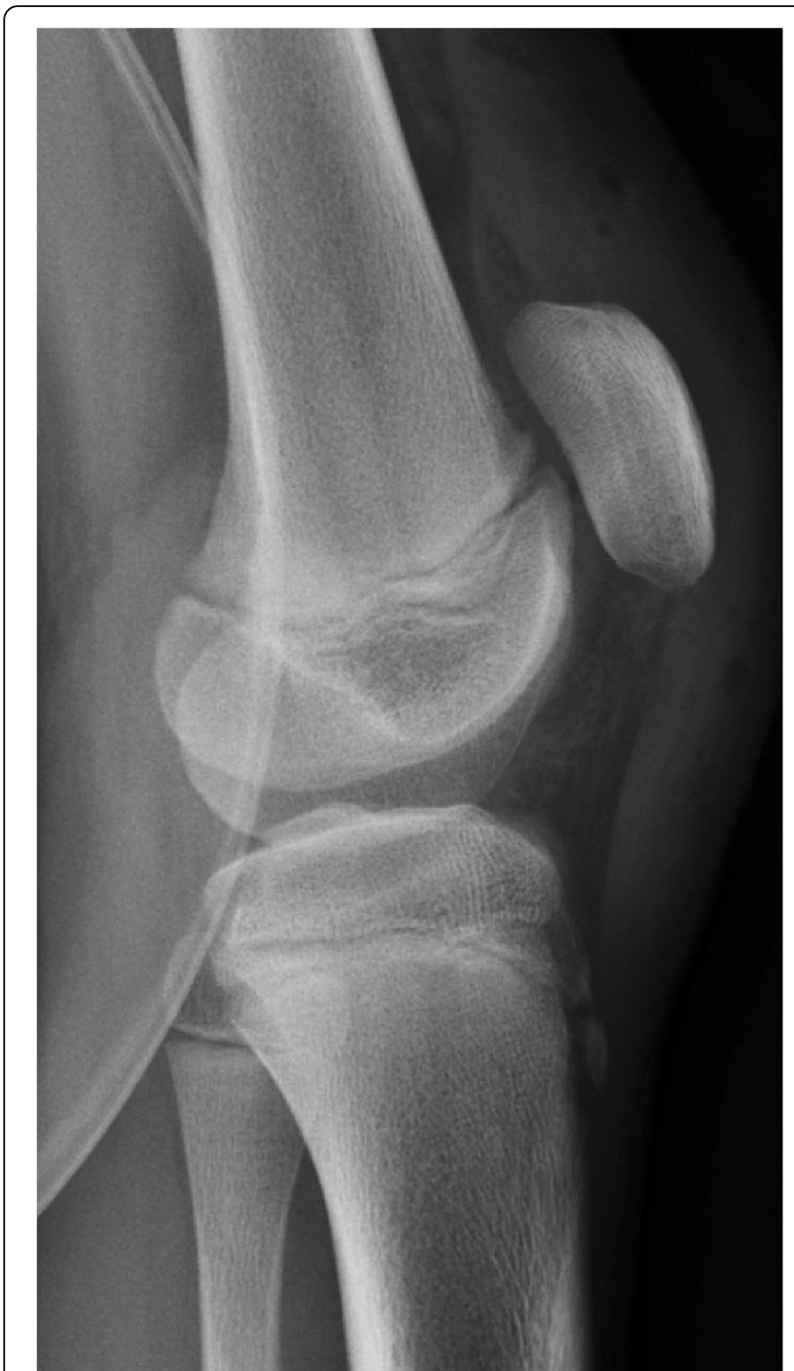

Fig. 7 Postoperative X-ray shows a correct patellar height

in a 12-year-old athlete with previous SLJ syndrome. Before acute PSA, our patient reported several months of anterior knee pain and tenderness over the inferior patellar pole after repetitive jumping activity.

In young patients, tibial tuberosity fractures are often preceded by various degrees of OsgoodSchlatter disease (OSD) [10]. Both OSD and SLJ syndrome are disorders seen in repetitive stress conditions, but there are no reports of SLJ syndrome with an increased fracture risk of the lower patellar pole. SLJ is an enchondral ossification disorder of the inferior pole of the patella, and is part of the osteochondrosis spectrum of diseases first described Sinding-Larsen and Johansson almost simultaneously in the 1920s [11]. Contrary to PSA, SLJ causes chronic pain and functional impairment of the knee in adolescent athletes in the same age group but without having suffered an acute trauma. Local inflammatory signs of the inferior pole of the patella and patellar tendon are present on physical examination [12]. Radiographic images of bone fragmentation in the distal pole appear within weeks of onset of symptoms, which have been described in 4 stages [13].

Sagittal MR images are useful in differentiating SLJ syndrome from PSA. Only a bony avulsion at the inferior patellar insertion is identified in the former entity, while the latter may present an extensive cartilaginous injury in addition to the osseous deformity [14]. The patient in this case had a complete disruption of the periosteum over the body of the patella with intact cartilage and a subtle bony avulsion in the inferior patellar pole and lateral retinaculum, barely visible on plain radiographs (Figs. 2, 3 and 4). Distinguishing between these entities is challenging and important with regard to patient treatment. Minimally displaced fractures such as those seen with SLJ syndrome are almost always managed conservatively and nonoperatively [15].

Closer attention to PSA fractures has been given only recently in literature since it was described in a case series by Houghton et al. in 1979 [8]. Only very rarely reported in adults [16], this entity is seen in skeletally immature patients that suffer an indirect pull of the extensor mechanism, where a small subchondral osseous fragment avulses together with an extensive sleeve of cartilage and periosteum from the main body of the patella. These fractures may occur in the entire circumference of the patella, and are described as superior, inferior, medial and lateral avulsions [9]. The unusual nature of our case is that the repetitive jumping mechanism led to a chronic overload of the extensor mechanism and ultimately to a PSA. It is not known if this entity is an advanced form of SLJ syndrome, and literature lacks studies that report direct causality.

Misdiagnosis is an unfortunate and frequent problem encountered with PSA. Prompt clinical diagnosis is important because clinical signs may be subtle. The clinicians should be aware of the risk factors and interrogate the patient thoroughly about the mechanism of injury. Not all patients have large effusions, decreased flexion or a clear disruption of the extensor mechanism. Non-displaced PSA with an intact posterior cartilaginous hinge will not necessarily lead to an active extensor lag. A high-riding patella or a palpable gap are clear signs of a displaced PSA in patients with severely swollen and tender knees [3]. Delay of diagnosis can result in suboptimal management and outcomes in displaced PSA [17]. If left untreated, a distal pull of the potent 


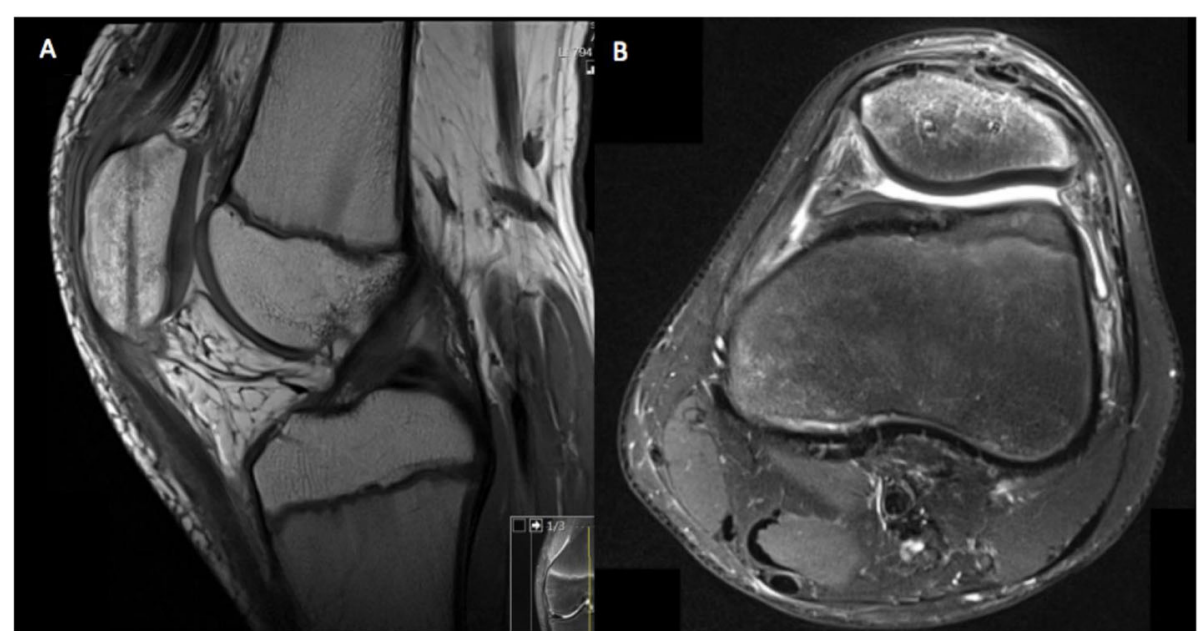

Fig. 8 a, b: Postoperative T1-weighted sagittal and T2-weighted axial MR images showing healed periosteum and sleeve avulsion from inferior pole of the patella

bone-forming tissue at the distal pole may go on forming bone and lead to an enlarged or even duplicated patella, active extensor lag and quadriceps muscle atrophy $[3,18]$.

Most authors agree that $>2 \mathrm{~mm}$ displaced PSA should be managed with open reduction and internal fixation in order to avoid the before mentioned complications. Treatment options vary because these fractures are uncommon, but good functional results are achieved with different techniques described in literature $[2,8,9,19]$. The use of trans osseous nonabsorbable sutures alone are the preferred surgical treatment in our institution, in order to avoid a second step procedure seen in patients treated with cerclage wire augmentation [3] or tension band wiring with metal $[20,21]$. We used two suture tapes (FiberTape ${ }^{\circ}$ and TigerTape ${ }^{\mathrm{Tx}}$ ) shuttled through 2 vertical bone tunnels in the patella in order to repair the avulsed periosteum and patellar tendon. We believe this technique is strong enough to withhold shear stress and eccentric loads allowing the patient to initiate an early rehabilitation regime. The use of non absorbable ultra strength sutures also decreases the risk of suture rejections and persistent wound drainage related to absorbable suture materials [8]. Absorbable and metal suture anchors $[22,23]$ and absorbable suture materials [24] are also frequently used surgical methods with good clinical outcomes.

\section{Conclusion}

This paper and literature review has highlighted a case of distal pole PSA fractures in a young athlete with previous SLJ syndrome. Whether this syndrome seen in repetitive stress conditions increases the risk of sustaining a PSA is still not clear. Patella sleeve fractures in skeletally immature patients are difficult to detect and easy to overlook on plane radiographs. Awareness of typical characteristics of patient's history, clinical examination and MRI are necessary for correct diagnosis. Early diagnosis and treatment with trans osseous fixation with suture tapes renders good functional results in a young athlete.

\section{Abbreviations}

PSA: Patellar sleeve avulsion; MRI: Magnetic Resonance Imaging; SLJ: SindingLarsen-Johansson; X-ray: Plain radiographs; OSD: Osgood-Schlatter disease

\section{Acknowledgements}

Not applicable.

\section{Authors' contributions}

AS $-\mathrm{H}^{1}$ participated in the study design, conducted the literature search and drafted the manuscript. FE ${ }^{1}$ drafted the manuscript, assisted in the literature search and obtained data, images during surgery and clinical follow-up and $V{ }^{1}$ assisted in the literature search and obtained data, images during surgery and clinical follow-up. $\mathrm{AA}^{1}$ and $\mathrm{Al}^{1}$ critically revised the manuscript. All authors read and approved the final manuscript.

\section{Funding}

Not applicable.

Availability of data and materials

All data concerning the case report are contained within the manuscript.

Ethics approval and consent to participate

Ethics committee of the medical faculty (Klinikum rechts der Isar, Technical University of Munich, Germany) approved this study for publication (reference number 160/18 s).

\section{Consent for publication}

Written informed consent was obtained from the patients' mother for publication of this case report and any accompanying images. A copy of the written consent is available for review by the Editor of this journal. The datasets used and analyzed during the current study are available from the corresponding author on reasonable request. 


\section{Competing interests}

The authors declare that there are no financial or personal conflicts of interests that could have influenced this work.

\section{Author details}

'Clínica Alemana de Santiago, Departamento de Ortopedia y Traumatología, Av. Vitacura 5951, Santiago de, Chile. ${ }^{2}$ Technical University of Munich. Klinikum rechts der Isar, Abt. f. Sportorthopädie- Ismaninger Str. 22, 81675 Munich, Germany. ${ }^{3}$ Klinik für Unfall- und Wiederherstellungschirurgie, BG Klinikum Bergmannstrost, Marseburger Str. 165, 06112 Halle/Saale, Germany.

Received: 4 March 2020 Accepted: 17 April 2020

Published online: 23 April 2020

\section{References}

1. Bates DG, Hresko MT, Jaramillo D. Patellar sleeve fracture: demonstration with MR imaging. Radiology. 1994;193:825-7.

2. Hunt DM, Somashekar N. A review of sleeve fractures of the patella in children. Knee. 2005;12:3-7.

3. Guy SP, Marciniak JL, Tulwa N, Cohen A. Bilateral sleeve fracture of the inferior poles of the patella in a healthy child: case report and review of the literature. Adv Orthop. 2011;2011:1-4.

4. Gettys FK, Morgan RJ, Fleischli JE. Superior pole sleeve fracture of the patella. Am J Sports Med. 2010;38:2331-6.

5. Ray JM, Hendrix J. Incidence, mechanism of injury, and treatment of fractures of the patella in children. J Trauma. 1992;32:464-7.

6. Duri ZAA, Patel DV, Aichroth PM. The immature athlete. Clin Sports Med. 2002;21:461-82-ix.

7. Seybold D, Hopf F, Kälicke T, Schildhauer TA, Muhr G. Sleeve fractures of the lower pole of the patella. Unfallchirurg. 2005;108:591-6.

8. Houghton GR, Ackroyd CE. Sleeve fractures of the patella in children: a report of three cases. The journal of bone and joint surgery. Br Vol. 1979;61-B:165-8.

9. Grogan DP, Carey TP, Leffers D, Ogden JA. Avulsion fractures of the patella. J Pediatr Orthop. 1990;10:721-30.

10. Frey S, Hosalkar H, Cameron DB, Heath A, David Horn B, Ganley TJ. Tibia tuberosity fractures in adolescents. J Child Orthop. 2008;2:469-74.

11. Sinding-Larsen MF. A hitherto unknown affection of the patella in children. Acta RadiolSAGE PublicationsSage UK: London, England. 2013;1:171-3.

12. López-Alameda S, Alonso-Benavente A, de Salazar AL-R, Miragaya-López P, Olmo JAA-D, González-Herranz P. Sinding-Larsen-Johansson disease: analysis of the associated factors. (Revista Espa) /ntilde glyphshow (Ola de Cirugía Ortopédica y Traumatología Neurología) (English edition). SECOT. 2012;56:354-60.

13. Medlar RC, Lyne ED. Sinding-Larsen-Johansson disease. Its etiology and natural history. J Bone Joint Surg-Am Vol. 1978;60:1113-6.

14. Gottsegen CJ, Eyer BA, White EA, Learch TJ, Forrester D. Avulsion fractures of the knee: imaging findings and clinical significance. RadioGraphics. 2008;28:1755-70.

15. Kodali P, Islam A, Andrish J. Anterior knee pain in the young athlete: diagnosis and treatment. Sports med Arthrosc rev. Sports Med Arthrosc Rev. 2011;19:27-33

16. Xie $L, X u H$, Zhang $L$. Sleeve fracture of the adult patella: case report and review of the literature. Medicine (Baltimore). 2017;96(32):e7096.

17. Damrow DS, Van Valin SE. Patellar sleeve fracture with ossification of the patellar tendon. OrthopedicsSLACK Incorporated. 2017;40:e357-9.

18. Bruijn JD, Sanders RJ, Jansen BR. Ossification in the patellar tendon and patella Alta following sports injuries in children. Complications of sleeve fractures after conservative treatment. Arch Orthop Trauma Surg. 1993;112:157-8.

19. Dai LY, Zhang WM. Fractures of the patella in children. Knee surgery, sports traumatology, arthroscopy. Springer-Verlag. 1999;7:243-5.

20. Gao GX, Mahadev A, Lee EH. Sleeve fracture of the patella in children. J Orthop Surg (Hong Kong)SAGE PublicationsSage UK: London, England. 2008;16:43-6.

21. Tsubosaka M, Makino T, Kishimoto S-I, Yamaura K. A case report of sleeve fracture of the patella in a shield. J Orthop Case Rep. 2016;6:24-7.

22. Gupta RR, Johnson AM, Moroz L, Wells L. Patellar sleeve fractures in children: a case report and review of the literature. Am J Orthop. 2006;35: 336-8.

23. Kumar K, Knight DJ. Sleeve fracture of the superior pole of the patella: a case report. Knee Surg Sports Traumatol Arthrosc. 2005;13:299-301.

24. Kaivers P, Busch T, Lies A. An avulsion (sleeve) fracture of the proximal patella pole in a child. Diagnosis, treatment and results in a patient after a fall onto the knee. Unfallchirurg. 2003;106:676-9.

\section{Publisher's Note}

Springer Nature remains neutral with regard to jurisdictional claims in published maps and institutional affiliations.

\section{Ready to submit your research? Choose BMC and benefit from:}

- fast, convenient online submission

- thorough peer review by experienced researchers in your field

- rapid publication on acceptance

- support for research data, including large and complex data types

- gold Open Access which fosters wider collaboration and increased citations

- maximum visibility for your research: over $100 \mathrm{M}$ website views per year

At $\mathrm{BMC}$, research is always in progress.

Learn more biomedcentral.com/submissions 